\title{
اللغة العربية والهوية الإسلامية
}

Araştırma Makalesi

\author{
Lahrech Assaad ELMAHACEN*
}

Makale Geliş: 13.03.2019

Makale Kabul: 03.12.2019

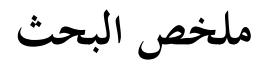

إن لذذا البحث أهمية كبرى؛ لأنه يتعلق بأمر مهم يمس المسلم في عنوان هويته الإسلامية ألا وهي لغته العربية، التي من خلالما يفهم قرآنه ويتعبد ربه، فهي لغة دين وحضارة وعلم وثقافة .

والذي دفع الباحث إلى كتابة هذا البحث ما لمسه من عزوف عن اللغة العبية عند كثير من الناس في هذا العصر، والمبالغة بالاهتمام باللغات الأخرى على حساب لغة القرآن، فنجد بعض الكليات أصبحت اللغة الإنجليزية اللغة المعتمدة في التدريس، وأصبح أغلب الناس يوجهون أبناءهم لدراسة اللغات الأخرى على حساب اللغة العربية.

وقد أكد البحث منزلة اللغة العربية في الشريعة الإسالمية ، والدليل على عظم

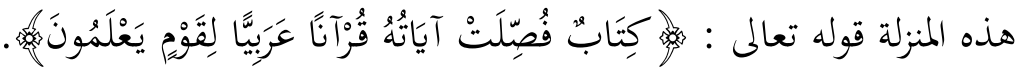

\footnotetext{
* Prof. Dr., Câmia'tu Zeyyân Â'şûr el-Celfe el-Cezâir, lahrech12@yahoo.fr, ORCID: 0000-0002-7870-795X

Atıf için; Lahrech Assaad ELMAHACEN, “Arapça Dili ve İslâmî Kimlik”, Yakın Doğu Üniversitesi İlahiyat Fakültesi Dergisi 5, sy. 2 (2019): 239256, DOI: https://doi.org/10.32955/neu.ilaf.2019.5.2.03 


$$
\begin{aligned}
& \text { وارتباط اللغة العربية بمصدر الإسالام الأول كتاب الله، جعل لها وثيق الصلة } \\
& \text { بالهوية الإسالمية، فهي لغة فكر وعقيدة، ولا يفهم الدين، ولا تدرك مقاصده } \\
& \text { إلا عن طريقها } \\
& \text { وقد اقترح البحث بعض الحلول لاستعادة ريادة هذه اللغة ، منها : دعم اللغة } \\
& \text { العربية ، بأن تكون لغة بعض العلوم الحلديثة من الطب والهندسة وغيرهما ، } \\
& \text { وذلك بترجمة مثل هذه العلوم باللغة العربية . ينبغي على الأمة العربية } \\
& \text { والإسالامية أن تنشر اللغة العبية في كل أرجاء الدنيا بكل الوسائل المتاحة . } \\
& \text { من أهم نتائج البحث : }
\end{aligned}
$$

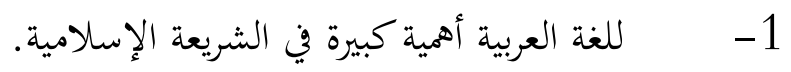

$$
\begin{aligned}
& \text { 2- - كانت اللغة العربية من أهم اللغات للناس في زمن فضة الأمة } \\
& \text { الإ سالامية. } \\
& \text { 3- - اللغة العربية أحد ركائز الموية الإسلامية. } \\
& \text { الكلمات المفتاحية: اللغة العربية، الموية الإسلامية، منزلة اللغة العربية، }
\end{aligned}
$$

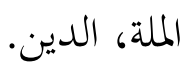

\section{Arapça Dili ve İslâmî Kimlik}

Öz

Bu araştırma büyük önem taşımaktadır. Çünkü araştırma, müslümana Kur'anı anladığı ve Allah'a ibadet ettiği dil olan Arapçanın İslami kimliğine dokunan önemli bir şeyle ilgilidir. Arapça, din, medeniyet, bilim ve kültür dilidir. Araştırmacının bu araştırmayı yazmasına yol açan, bu dönemde birçok insanın Arapça dilinin isteksizliği olduğunu ve Kur'an dili pahasına diğer dillere dikkatini abarttığını, bazı kolejlerin İngilizceyi dil olarak kabul ettiğini tespit edilmiştir. Çoğu kişi artık çocuklarını Arapça pahasına başka dilleri okumaya yönlendiriyor. Araştırma, İslam hukukunda Arap dilinin durumunu ve bu statünün büyüklüğünün Allah'ın yüce sözleriyle doğrulandığını doğrulamıştır: " $\mathrm{Bu}$, bilen bir toplum için Arapça bir Kur'an olarak ayetleri genişçe açıklanmış bir kitaptır.” (Fussilet 3). 
Arapça ile İslam'ın kaynağı olan Allah'ın kitabı arasındaki bağlantı, onu İslami kimlikle yakından ilişkilendirmiştir. Araştırma, aşağıdakiler de dâhil olmak üzere, bu dilin öncülüğünü geri kazanmaya yönelik bazı çözümler önermiştir. Arapça dili, bu tür bilimleri Arapça'ya çevirerek bazı modern tıp, mühendislik ve diğer bilimlerin dili haline getirilmelidir.

Araştırmanın en temel sonuçları:

1. Arapça, İslam hukukunda çok önemlidir.

2. Arapça, İslam ümmetinin kalkınması döneminde insanlar için en önemli dillerden biridir.

3. Arapça, İslami kimliğin temellerinden biridir.

Anahtar Kelimeler: Arapça, İslam kimliği, Arapça dilinin durumu, Millet, Din

\section{Arabic Language and Islamic Identity}

\section{Abstract}

This research is of great importance, because it concerns an important thing that touches the Muslim in his Islamic identity, which is the Arabic language, through which he understands the Koran and worships Allah, it is the language of religion, civilization, science and culture.

Which led the researcher to write this research is the reluctance of the Arabic language of many people in this era, and exaggerated attention to other languages at the expense of the language of the Koran, we find that some colleges have adopted English as the language of study, and most people now direct their children to study other languages at the expense of Arabic.

The research confirmed the status of the Arabic language in Islamic law, and the evidence of the greatness of this status in these words of Almighty :

"A Book whose verses have been detailed, an Arabic Qur'an for a people who know" (Fussilat 3)

The link between Arabic and the source of Islam, the first book of Allah, made it closely related to the Islamic identity. The research suggested some solutions to restore the leadership of this language, including: Supporting the Arabic language, to be the language of some modern sciences of medicine, engineering and others, by translating such sciences in Arabic. The Arab and 
Top search results:

1. Arabic is of great importance in Islamic law.

2- Arabic was one of the most important languages for people in the time of the renaissance of the Islamic nation.

3. Arabic is one of the pillars of Islamic identity.

Keywords: Arabic language, Islamic identity, Arabic status, National, Religion

المقلدمة

الحمد لله رب العالمين والصلاة والسلام على الهادي البشير، يدور موضوع هذا البحث حول اللغة العربية من حيث مكانتها وسبل دعمها والمحافظة عليها، ثم بيان أهم الحلول لدعم اللغة العربية وإعادها لدورها الرائد، ومن هنا جاء عنوان البحث: " اللغة العربية ومنزلتها في الثريعة الإسلامية". أهداف البحث يهدف الباحث من خلال هذا البحث إلى الكشف عن:

\section{بيان أهمية ومنزلة اللغة العربية في الشريعة الإسلامية.}

بيان صلة اللغة العربية بالفؤية الإسلامية.

أهم الحلول للنهوض باللغة العربية.

مشكلة البحث: تكمن مشكلة هذا البحث فيما لمسه الباحث من عزوف

عن اللغة العربية عند كثير من الناس في هذا العصر، والمبالغة بالاهتمام باللغات الأخرى على حساب لغة القرآن، فنجد بعض الكليات أصبحت اللغة الإنجليزية اللغة المعتمدة في التدريس، وأصبح أغلب الناس يوجهون أبناءهم لدراسة اللغات الأخرى على حساب اللغة العربية، وعند حديثه مع بعض الأكاديميين حول علاقة اللغة العربية والهوية الإسلامية، فقد صرح بعضهم بأن اللغة العربية مجرد لغة للتواصل وهي

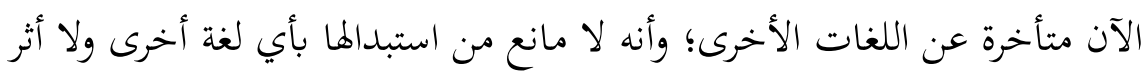


لذلك على هوية المسلم، ومن هنا جاء سؤال البحث هل اللغة العربية مجرد لغة للتخاطب والتواصل أم أن لها منزلة ومكانة كبيرة في الشريعة الإسلامية؟.

أهمية البحث: لا شك أن لهذا البحث أهمية كبرى؛ لأنه يتعلق بأمر مهم يمس المسلم في عنوان هويته الإسلامية ألا وهي لغته العربية، التي من خلالما يفهم قرآنه ويتعبد ربه، فهي لغة دين وحضارة وعلم وثقافة ؛ فمثل هذا البحث يسلط الضوء على أهم قضايا المسلم ومن خلاله يفهم حجم الغزو الفكري الذي يواجه الأمة في لغتها وأهم ثوابتها، فأمة لا تحافظ على لغتها تضيع بين الأمم وينعدم لها وجود وحضور ·

منهجية البحث: استخدم الباحث المنهج الوصفي التحليلي، وهو المنهج المناسب لهذه الدراسة،حيث يقوم على دراسة الظاهرة والمشكلة العلمية من خلال القيام بالوصف بطريقة علمية، ومن ثم الوصول إلى تفسيرات منطقية وبراهين تمنح الباحث القدرة على وضع الحلول المناسبة للمشكلة، كما قام الباحث بتخريج الآيات القرآنية مع الالتزام برسم المكتبة الشاملة، للخروج من مشكلة اختلاف الخطوط من جهاز لآخر، كذلك قام الباحث بعزو النقولات إلى أصحابها التزاماً بالأمانة العلمية التي تقتضي ذلك، ولم يقم الباحث بالترجمة للأعلام الوارد ذكرهم في البحث نظراً لكثرقم مع ضيق المقام هنا، وطلباً للاختصار.

هيكلية البحث: قسم الباحث هذه الورقة إلى: مقدمة وثلاث مباحث الأول

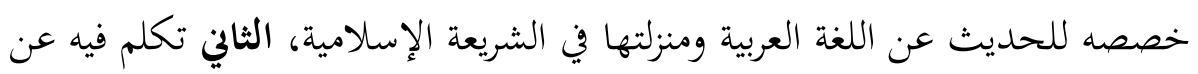
اللغة العربية وهوية الأمة الإسلامية، والثالث خصصه لأهم الحلول للنهوض باللغة العربية ، وهو عبارة عن مقترح وتوصية للنهوض باللغة العربية والقيام بواجبها، تم خاتمة ذكر فيها أهم نتائج البحث. 


\section{المبحث الأول: منزلة اللغة العربية في الشريعة الإسلامية}

تعد اللغة العربية أحد اللغات الإنسانية القديمة المشهورة؛ فقد تكلمت بها أمم سابقة كعاد وتمود وجرهم، وكانت اللغة العربية منتشرة في اليمن والعراق، واستقرت في الحجاز، وقد بلغت اللغة شهرتا وأهميتها عندما اختارها الله سبحانه وتعالى لغة

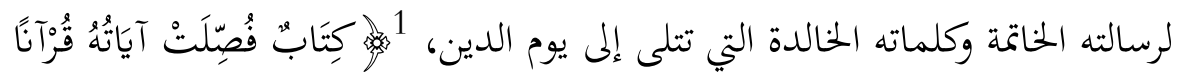

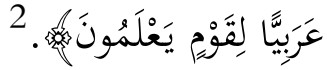

وللغة العربية منزلة ومكانة عظيمة في الشريعة الإسلامية، ولا غرابة في ذلك فهي لغة القرآن الكريم، ولا يتأتى فهمه إلا من خلالها وهي الوسيلة الوحيدة للتدبر

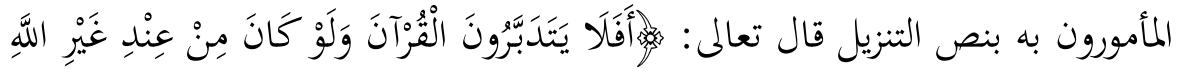

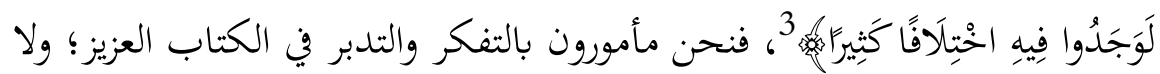
يتأتى هذا بدون فهم اللغة العربية والإلمام بها، وكيف يتأتى لنا فهم الكتاب العزيز والإيمان بكل ما جاء فيه دون فهم لغته، وإن قراءة القرآن من الأمور النافعة التي يجازى عليها المسلم عند الله خير الجزاء، والمسلم في العموم محتاج للغة العربية في فهم القرآن وأداء العبادات؛ فمن هنا تكون الأهمية كبيرة والحاجة ماسة للغة العربية. ومما يدل على علو مكانتها في الشريعة الإسلامية كثرت الإشارة لما في القرآن العظيم، فقد أشار القرآن في العديد من الآيات إلى العربية واللسان العربي، قال

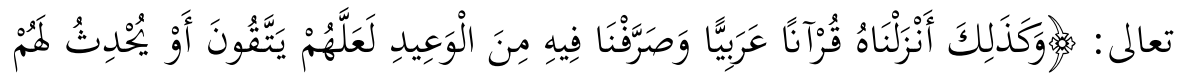
ذِكُرًا (113)

1 سورة فصلت الآية 3.

2 أهمية اللغة العربية، أحمد بن عبد الله الباتلي، دار الوطن للنشر -الرياض، 1412هـ، ص 9. 3و سورة النساء الآية 82.

4 سورة طه: الآية 113.

5 سورة الزمر الآية 28. 


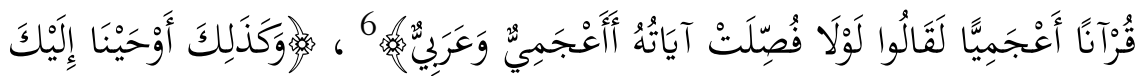

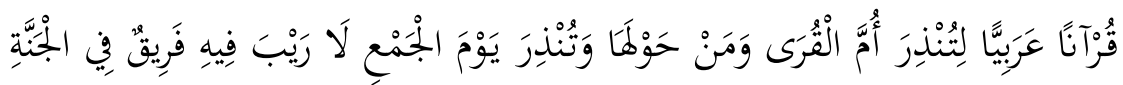

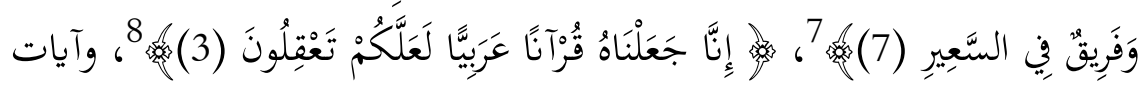

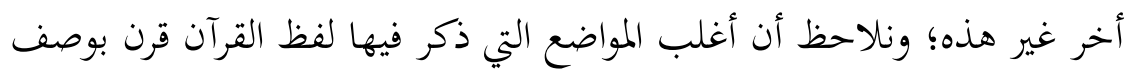

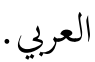

وللغة العربية أهمية كبيرة في جمع المسلمين ووحدقم، لذا ينبغي أن تولى أهمية

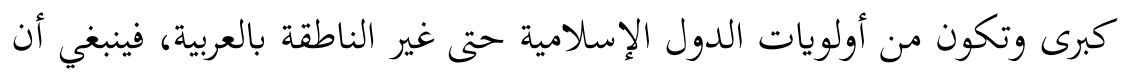
تدرس وتعاد صياغة مناهجها بحيث تتوافق ومتطلبات العصر، وتكون على قدر

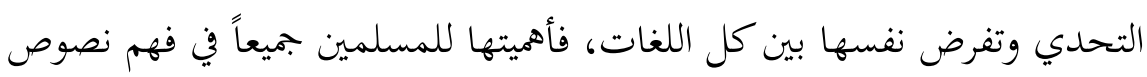

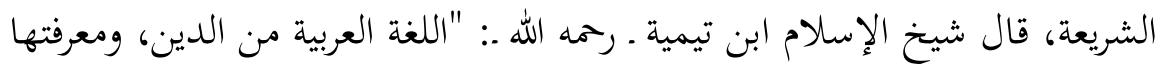

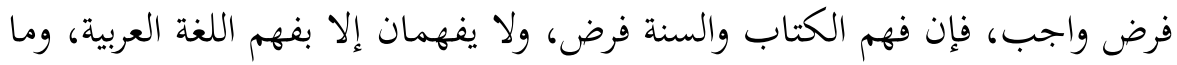

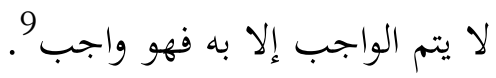

ومما يدلل على أهمية ومكانة اللغة العربية نسبتها للقرآن وللدين الإسلامي

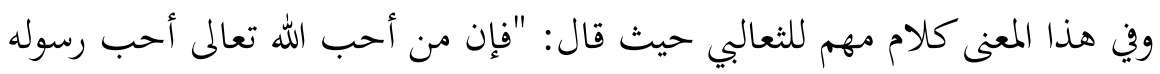

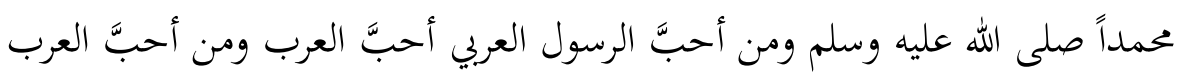

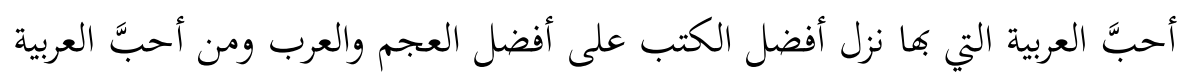

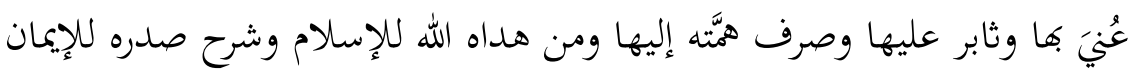

6 سورة فصلت الآية 44.

7 سورة الشورى الآية 7.

8 سورة الزخرف الآية 3.

9 اقتضاء الصراط المستقيم لمخالفة أصحاب الجحيم، ص صد 527. 
وآتاه حسن سريرة فيه اعتقد أن محمداً صلى الله عليه وسلم خير الرسل والإسلام خير

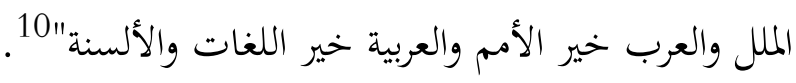

ومما يزيد اللغة العربية رفعة ومكانة أن الله جل في علاه تكفل بجفظها في قوله

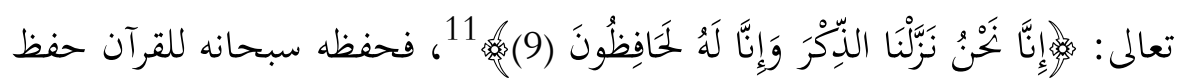
للغة التي نزل بها والله أعلم.

\section{المبحث الثاني: اللغة العربية والهوية الإسلامية}

اعتبار اللغة العربية من دعائم وركائز الهوية الإسلامية ليس باعتبارها لغة لأمة

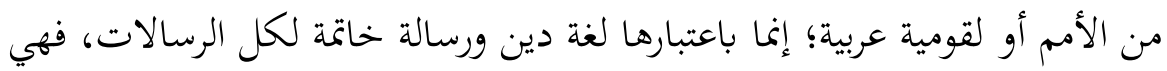

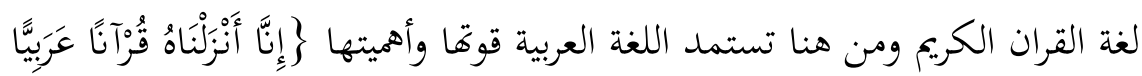

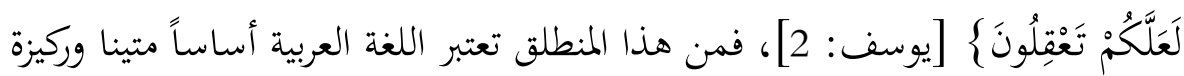
ثابتة من ركائز الهوية الإسلامية، تلي العقيدة والدين في الأهمية.

إذن فالحديث عن اللغة العربية هنا باعتبارها جزء من هذا الدين، وفهم

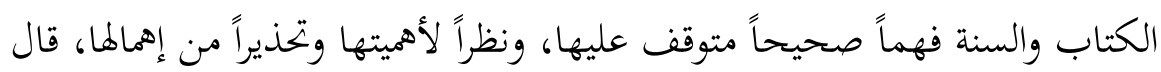

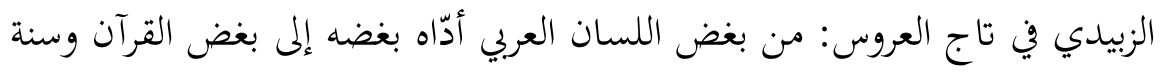

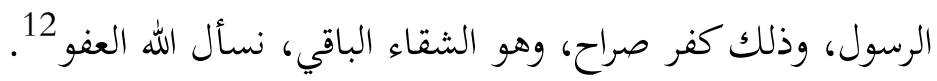

وارتباط اللغة العربية بكصدر الإسلام الأول كتاب الله، جعل لها وثيق الصلة

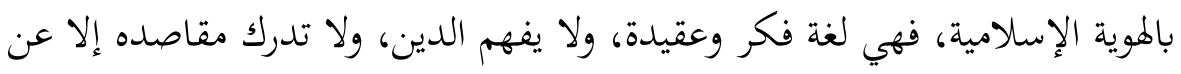

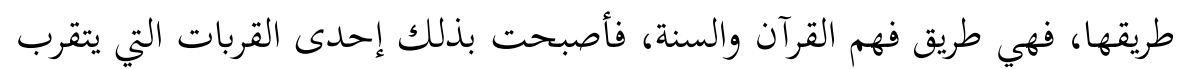

10 فقه اللغة وسر العربية، عبد الملك بن محمد بن إسماعيل أبو منصور الثعالبي، تحقيق: عبد الرزاق المهدي، دار

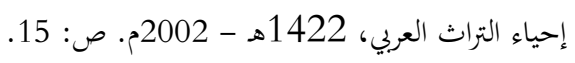
11 سورة الحجر الآية 9. 12 تاج العروس، الزبيدي 1/ 99. 
بها إلى الله تعالى بتعلمها، وقد قرر بعض العلماء أن تعلمها واجب، فما لا يتم الواجب إلا به فهو واجب.

وقد اشتملت اللغة العربية على كافة أصناف البلاغة والسمو اللغوي، وكان العرب قبل الإسلام يتكلمون على السليقة دون لحن، ولكن بعد بزوغ شمس الإسلام

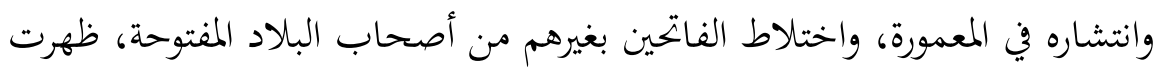
بوادر اللحن، الأمر الذي دفع الغيورين على دينهم للمسارعة في وضع قواعد تعصم اللسان من الخطأ أو اللحن في كتاب الله، وتساعد على فهمه، فجُمعت اللغة وتم ضبطها وتحديد ألفاظها، فأدى ذلك إلى ظهور المعاجم اللغوية ونشأة وازدهار علوم اللغة العربية، وظهرت المؤلفات في النحو والصرف والعروض...13.

وبهذا فإن اللغة العربية أحد أهم أسس الهوية الإسلامية، وليس من قبيل التعصب القومي وإنما هو انتماء للدين الإسلامي واعتزاز به، فهي اللغة التي جمعت أجناساً من البشر اختلفت لغتهم وأقطارهم وألوافم وأشكالهم، جمعتهم لغة القرآن الكريم تحت عقيدة واحدة ودين واحد.

المبحث الثالث: مقترح وتوصية: أهم الحلول للنهوض باللغة العربية

يوصي الباحث ببعض الوسائل والخطوات العملية التي تساهم في ترسيخ وتقوية ودعم اللغة العربية في العصر الحديث، ولتحقيق هذا الأمر ينبغي النظر للمسألة من جانبين: الجانب الأول دعم اللغة العربية، وليس معنى هذا أن اللغة ضعيفة في حد ذاتما؛ وإنما القصد دعمها بالعلوم الجديدة المعاصرة كالطب والهندسة وسائر العلوم المعاصرة التي قصرت الأمة في تحصيلها لأسباب عدة، ولعل أهم خطوة هي الترجمة من اللغات الأخرى للعربية، وهذه ليست طريقة جديدة وإنما قديمة بجربة عند

13 الهوية الإسلامية والتحديات التي تواجهها، الألوكة، رابط: http://www.alukah.net/publications_competitions/0/40298/\#_ftnref20 
غيرنا ولما نتائج قوية في النهضة على جميع الصعد، فمن المعلوم أن الغرب خرج من

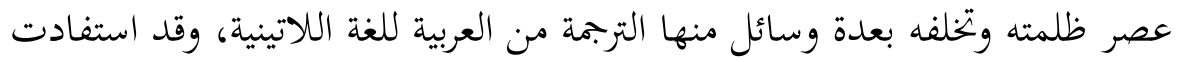

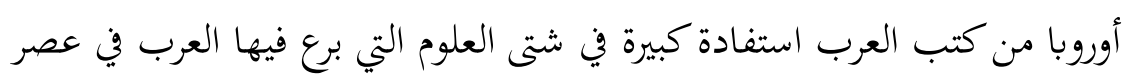

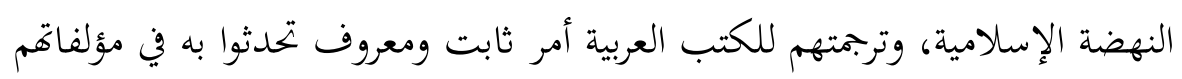

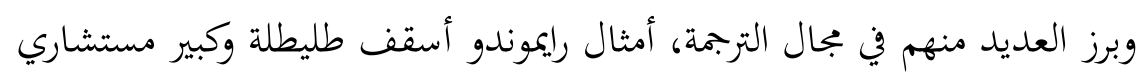

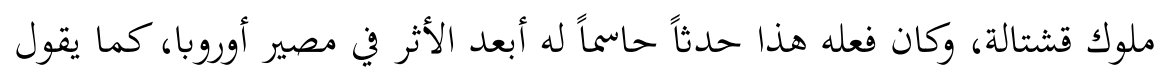
إرنست رينان.14. - إن.

وأمر الترجمة لم يكن فردياً وإنما ترعاه مؤسسات فعلى سبيل المثال المدرسة

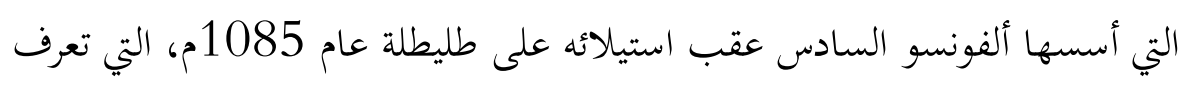

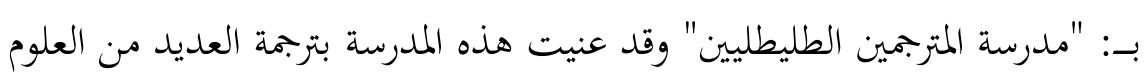

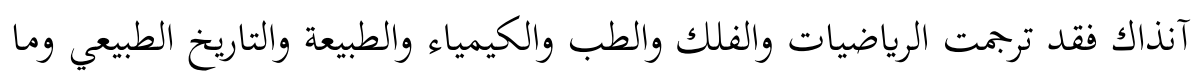

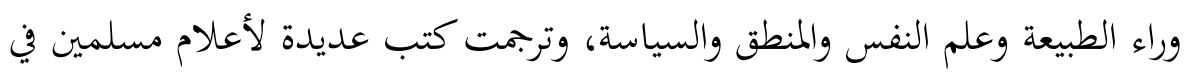

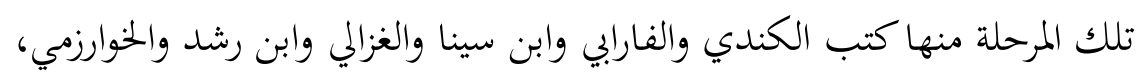

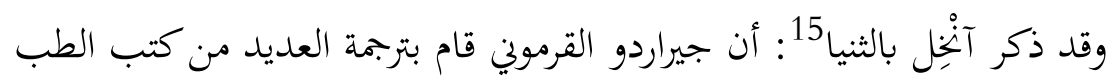

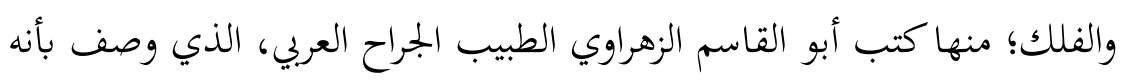

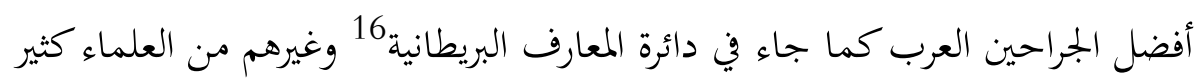
آنذاكـ

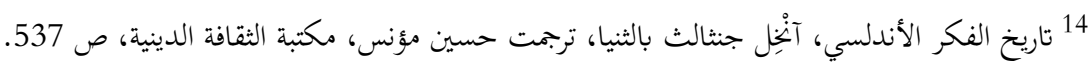
15 المصدر السابق ص 14 16 بغية الملتمس في تاريخ رجال أهل الأندلس (ص: 286) الأعلام للزركلي (2/ 310 310 الماند

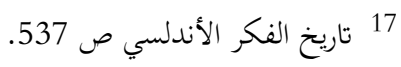


ولم تبق تلك الترجمات حبيسة الكتب والمكتبات وإنما انتشرت في أوروبا

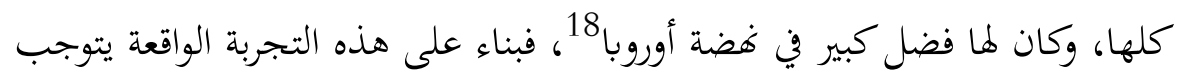
علينا أن نستفيد من بجارب غيرنا، وأن ننقل كل العلوم النافعة للغتنا العربية، كي تواكب هذا التطور العلمي المعاصر، وتنهض الأمة الإسلامية ويعود لها عصر ازدهارها وتقدمها، وأمر الترجمة لم يكن الغرب سباقاً له وإنما كانت بداياته منذ بداية تكوين الدولة الإسلامية فقد أمر الفاروق رضي الله عنه بتعريب النقود $19 ،$

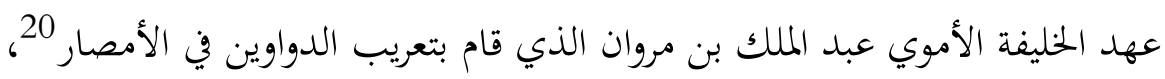
فمن هذا نعلم أهمية التمسك باللغة والاعتداد بها.

هذا فيما يخص الجانب الأول وهو دعم المكتبة العربية بجميع العلوم المعاصرة، أما الجانب الثاني وهو يتركز على نشر اللغة العربية بين جميع المسلمين ولو كانوا غير عرب؛ لأها لغة قرآفم ودينهم بها تصح عباداتم، وهي جسر التواصل بينهم وعنوان هويتهم، وهي اللغة التي اختارها المولى تبارك وتعالى لهذه الأمة الخاتمة لكل الأمم بأن

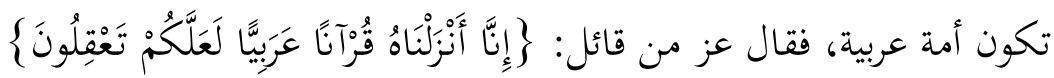
[يوسف: 2]، وهذا الحمل على عاتق الأمة العربية عليها أن تقوم به وتنشط فيه؛ فعليها أن تنشر اللغة العربية في كل مكان وبقعة على وجه البسيطة يدين أهلها بالإسلام، فأكثر الشعوب المسلمة من غير العرب لا يتكلمون العربية ولا يحسنوفا، فيجب على الدول العربية أن تدعمهم وتسهل عليهم تعلمها.

$$
18 \text { المصدر السابق ص } 1938 .
$$

19 160رائل المقريزي، أحمد بن علي بن عبد القادر، تقي الدين المقريزي، دار الحديث، القاهرة، 1418 هـ، ص

20 الأحكام السلطانية، أبو الحسن علي بن محمد البصري البغدادي، الماوردي، دار الحديث - القاهرة، ص: 
فدعم اللغة العربية والقيام بواجب نشرها ليس كوغا لغة تخاطب وتواصل

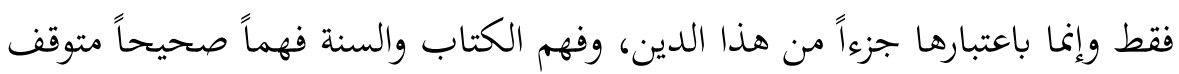

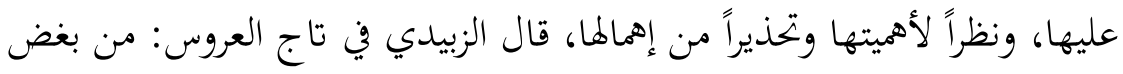

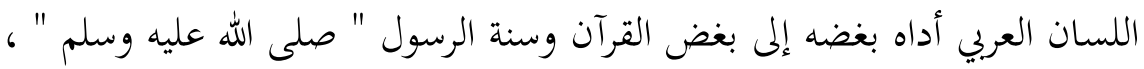
وذلك كفر صراح، وهو الشقاء الباقي، نسأل الله العفو 21.

ومما يجدر الإشارة به هنا الرد على من يزعمون أن اللغة العربية غير صالحة

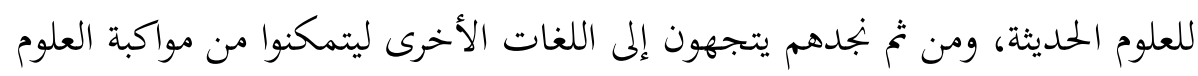

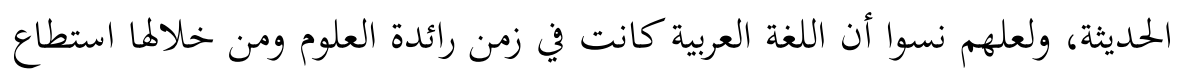

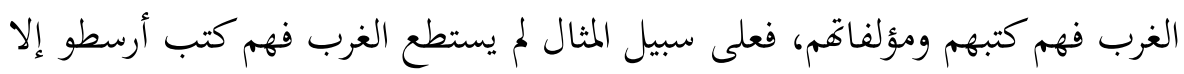

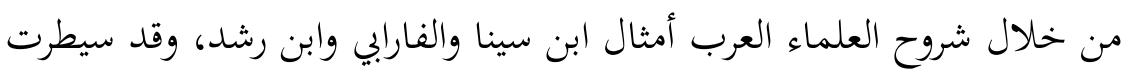

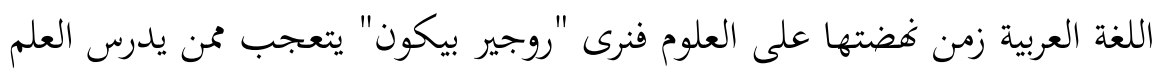

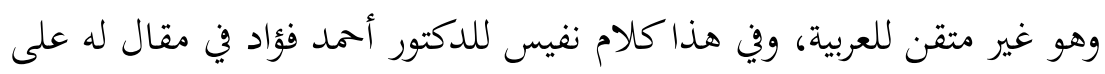

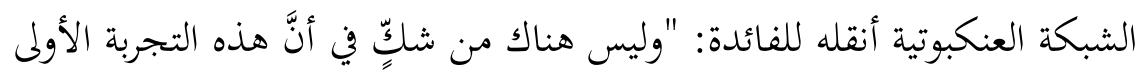

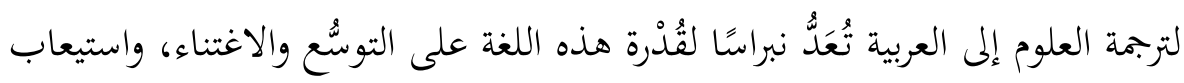

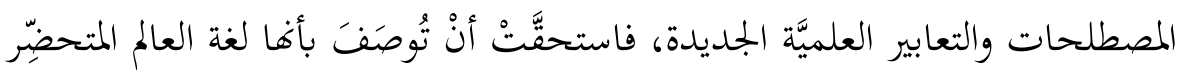

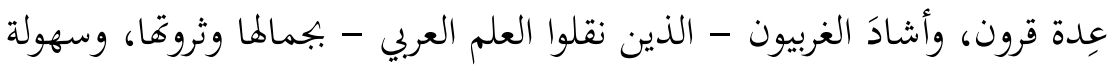

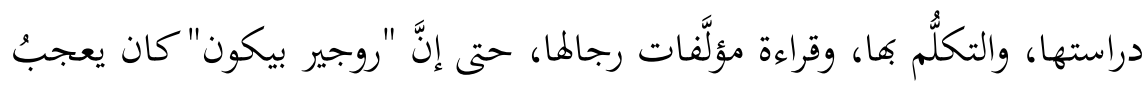

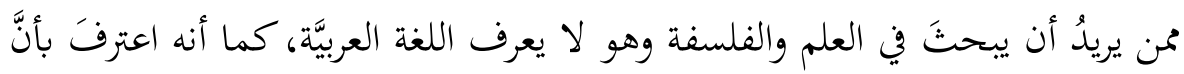

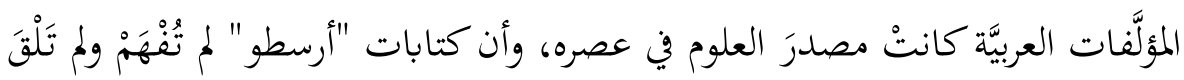

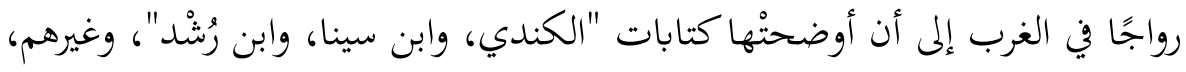

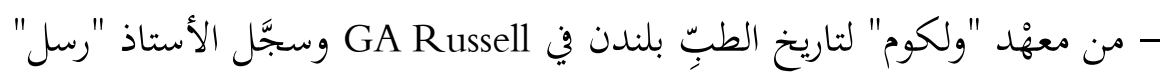

$$
21 \text { تاج العروس (1) - (99) }
$$


معجم حديث لتاريخ العلوم (1981) - المعالمٍ الأساسية للعلم العربي، ثم قال: "كانت اللغة العربية هي أداة هذا النشاط العلمي كلِّه، فلمَّا كانت اللغة العربية هي لغة

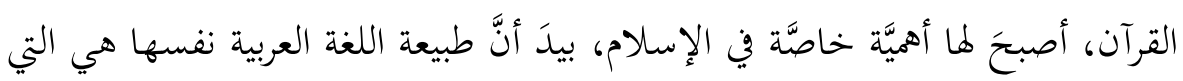

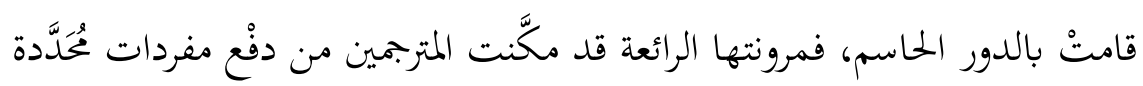

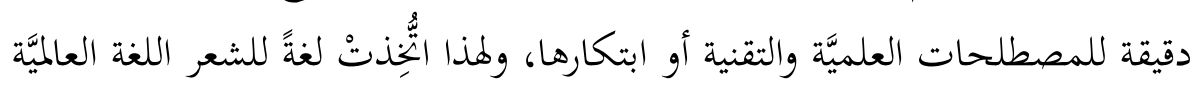

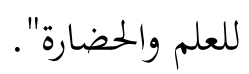
وهذه الإشارة إلى عالميَّة لغة العلم لفتة بارعة إلى فضْل اللغة العربيَّة يؤكِدهد المحققون من مؤرِّي العلم، ويغيبُ عن بال الكثيرين.

ولقد امتدَّ تأثير اللغة العربية في اللغات الحيَّة الأخرى؛ حيث يُحصي معجم - على سبيل المثال - عebster's third New International Dictionary أكثر من ستمائة ألف كلمة مأخوذة من اللغة العربية، منها خمسمائة كلمة فقط من الألفاظ المستعمَلة في الكتابة والأحاديث العادية، والباقي في الشؤون العلميَّة الفنيَّة، ومَن يتتَّبع تأثيرَ اللغة العربية في اللغات الأخرى، يجذْ لها آثارًا واضحة في الإسبانية، والبرتغالية، والفرنسية، والألمانية، وفي اللغات الجِرْمانيَّة الأصل، كالهولنديَّة والإسكندنافيَّة في شمال أوروبا، وفي الروسيَّة والبولنديَّة، واللغات الصقليَّة والإيطالية،

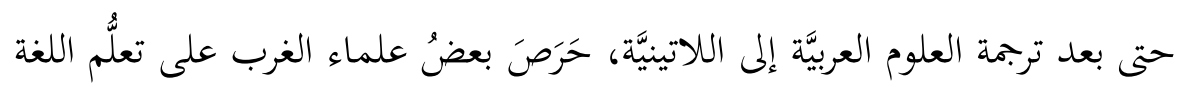

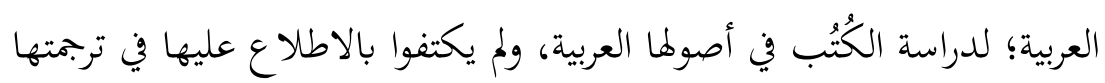

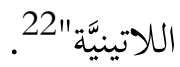

وعند هذا القدر نكفتي ولعل فيما سبق دلالة واضحة على أهمية اللغة العربية قديماً، وفيه الحل لعودة الريادة والسبق للغة العربية وذلك بالاهتمام بترجمة العلوم

22 موقع الألوكة، أحمد فؤاد، مقال بعنوان: ترجمة العلوم العربية إلى اللاتينية،: 2010/11/21 م - 1431/12/16

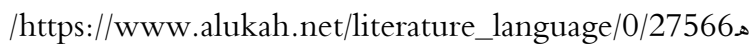


المعاصرة، وأن يكون عبر الجامعات والمراكز البحثية، وذلك بأن يدرس هذا الموضوع

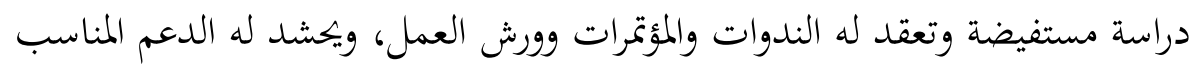

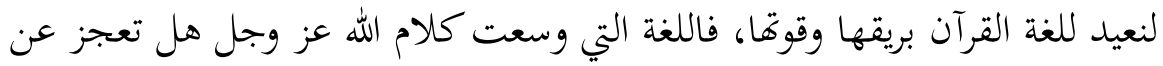

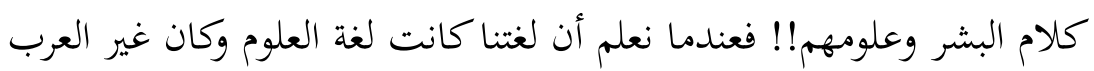

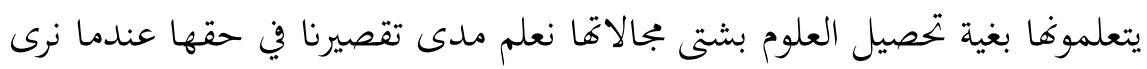

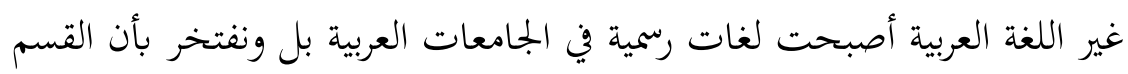

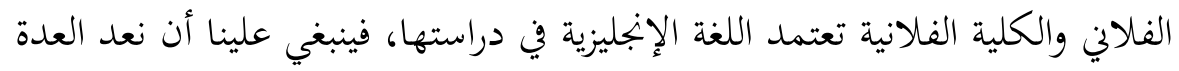

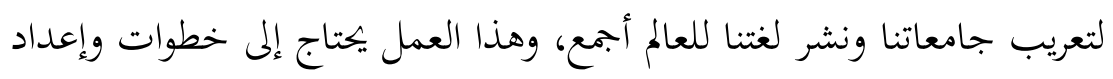
يسبقه.

الخاتمة

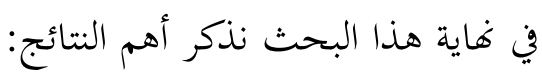

$$
\text { 1 - اللغة العربية أهمية كبيرة في الشريعة الإسلامية. }
$$

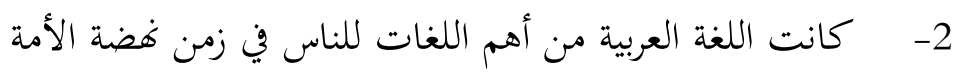

$$
\text { الإسلامية. }
$$

$$
\text { 3- اللغة العربية أحد ركائز الموية الإسلامية. }
$$

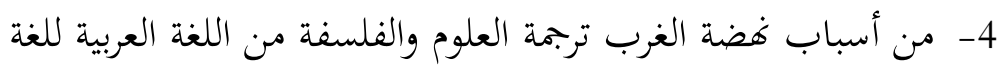

اللاتينية.

5- أهم داعم للغة العربية في العصر الحديث الترجمة للعلوم من اللغات

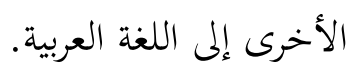




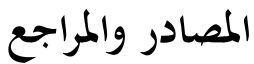

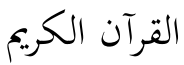

تاريخ الفكر الأندلسي، آنْخِل جنثالث بالثنيا، ترجمت حسين مؤنس، مكتبة الثقافة الدينية

تاج العروس من جواهر القاموس، محمّد بن محمّد بن عبد الرزّاق، الملقّب بمرتضى، الزَّبيدي، لمجموعة من المحققين، دار المداية.

بغية الملتمس في تاريخ رجال أهل الأندلس، أبو جعفر الضبي أحمد بن يحيى بن أحمد بن عميرة، دار الكاتب العربي - القاهرة 1967 م

الأعلام، خير الدين بن محمود بن محمد الزركلي، دار العلم للملايين، ط 15، 2002 اقتضاء الصراط المستقيم لمخالفة أصحاب الجحيم، تقي الدين أبوالعباس أحمد بن عبد

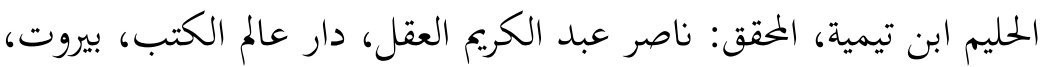
لبنان، الطبعة: السابعة، 1419هـ - 1999م.

رسائل المقريزي، أحمد بن علي بن عبد القادر، تقي الدين المقريزي، دار الحديث،

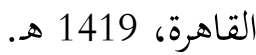

الأحكام السلطانية، أبو الحسن علي بن محمد البصري البغدادي، الماوردي، دار

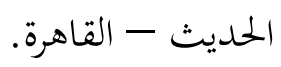

الهوية الإسلامية والتحديات التي تواجهها، الألوكة، رابط:

http://www.alukah.net/publications_competitions/0/40298/\#_ftnref20

فقه اللغة وسر العربية، عبد الملك بن محمد بن إسماعيل أبو منصور الثعالبي، تحقيق: عبد الرزاق المهدي، دار إحياء التراث العربي، 1422هـ - 2002م. 


\section{KAYNAKÇA}

Kur'ânu'l-Kerîm.

Abdulmelik b. Muhammed b. İsmâî'l Ebû Mansûr es-Seâ'libî. F1khu'l-Lüğa ve Sirru'l-A'rabiyye. tahkik: Abdurrezzâk elMehdî. Dâru İhyâi't-turâsi'l-A'rabî; 1422/2002.

Ahmed b. Ali b. Abdulkâdir, Teq1yyuddin el-Makrîzî. Resâilu'lMakrîzî. Dâru'l-hadîs, el-Kâhire, 1419 h.

Ebu Ca'fer ed-Dabî Ahmed b. Yahyâ b. Ahmed b. U'meyra. Buğyetu'l-mültemis fî târîhi ricâli ehli'l-endelüs. Dâru'lkâtibi'l-A'rabî, el-Kâhire 1967.

Ebu'l-Hasen Ali b. Muhammed el-Basrî el-Bağdâdî el-Mâverdî. elAhkâmu's-sultâniyye. Dâru'l-Hadîs, el-Kâhire, ty.

el-Hüviyyetu'l-İslâmiyye ve't-tehaddiyâtu'l-letî Tüvâcihuhâ, el-Elûke,

Râbit:(http://www.Alukah.net/publications_competitions/0/402 98/_ftnref20).

Gansalice Balisenya. Târîhu'l-fikri'l-Endelusî, Anhıl. terc. Huseyn Munis. Mektebetu's-seqâfeti'd-Dîniyye), ty.

Hayruddîn b. Muhammed b. Mahmûd b. Muhammed ez-Zeriklî. elA'lâm. Dâru'l-i'lim li'l-melâyîn, Tab'1: 15, 2002.

Muhammed b. Muhammed b. Abdurrezzâk el-mulekkab bi Murtedâ ez-Zebîdî. Tâcu'l-A'rûs min cevâhiri'l-Kâmûs li mecmûatin mine'l-muhakkıkîn, Dâru'l-hidâye, ty.

Tekiyyuddîn Ebu'l-Abbâs Ahmed b. Abdülhalîm b. Teymiye. Iktidâu's-sırâta'l-musteq1ym limuhâlefeti eshâbi'l-cehıym. elMuhakkik: Nâsır Abdülkerîm el-A'kl, Dâru Âlemi'l-kütüb,. Beyrût, Lübnân, et-Tab'a’tu's-sâbia', 1419/1999. 


\section{EXTENDED SUMMARY}

\section{ARABIC LANGUAGE AND ISLAMIC IDENTITY}

Research problem: The problem of this research is how many people of this age feel about the reluctance of the Arabic language and the exaggeration of interest in other languages at the expense of the Koran language. Therefore, many people have directed their children to learn English. The other, at the expense of the Arabic language and talking to some scholars about the Arabic language and the relationship between Islamic identity, some say that Arabic is only a language of communication, that it lags behind other languages and that it is $\mathrm{OK}$ to change it to another. Here's a question: If Arabic is just an ordinary language for communication, how do we explain its great place in Islamic law?

Which led the researcher to write this research is the reluctance of the Arabic language of many people in this era, and exaggerated attention to other languages at the expense of the language of the Koran ,we find that some colleges have adopted English as the language of study, and most people now direct their children to study other languages at the expense of Arabic. The research confirmed the status of the Arabic language in Islamic law, and the evidence of the greatness of this status in these words of Almighty:"A Book whose verses have been detailed, an Arabic Qur'an for a people who know" (Fussilat 3)

Research methodology: The researcher used a descriptive analytical approach, the appropriate method for this research. Because the phenomenon and the scientific problem, made the definition in a scientific way. Subsequently, the researcher finally reached logical interpretations and evidence that gave him the ability to develop appropriate solutions to the problem. 
Research Structure: The researcher divided this article in two: an introduction and three titles. The first is to talk about the Arabic language and its status in Islamic law. The second is about the Arabic language and the identity of the Islamic nation. The third is the most important solution for the advancement of the Arabic language.

This research is of great importance, because it concerns an important thing that touches the Muslim in his Islamic identity, which is the Arabic language, through which he understands the Koran and worships Allah, it is the language of religion, civilization, science and culture.

The link between Arabic and the source of Islam, the first book of Allah, made it closely related to the Islamic identity, it is the language of thought and doctrine, we can understand religion, and realize its purposes only through it. The research suggested some solutions to restore the leadership of this language, including: Supporting the Arabic language, to be the language of some modern sciences of medicine, engineering and others, by translating such sciences in Arabic. The Arab and Islamic nation should spread the Arabic language throughout the world by all available means.

Top search results:

1. Arabic is of great importance in Islamic law.

2 - Arabic was one of the most important languages for people in the time of the renaissance of the Islamic nation.

3. Arabic is one of the pillars of Islamic identity.

4. One of the reasons for the rise of the West was the translation of science and philosophy from Arabic into Latin.

5. The most important supporter of the Arabic language in the modern era is the translation of sciences from other languages into Arabic. 